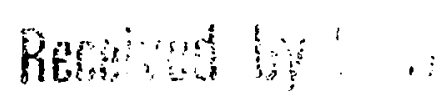

APR 241991
The suberitud menuectipi has beth suthosed or e centretio of the U. E. Gerrnment

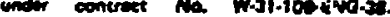

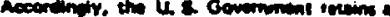

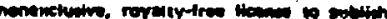

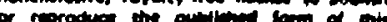

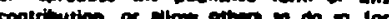
U. S. Gowrniment purpoint.

ANL/CP--70911

DE91 010791

\title{
PROTECTION AGAINST UVA-INDUCED PHOTOOXIDATIVE DAMAGE IN MAMMALIAN CELL LINES EXPRESSING INCREASED LEVELS OF METALLOTHIONEIN
}

\author{
Edward J. Dudek ${ }^{\star t}$, Jennifer G. Peak", Robert M. Roth', and Meyrick J. Peak
}

'Biological and Medical Research Division, Argonne National Laboratory, Argonne, Illinois and 'Department of Biology, Illinois Institute of Technology, Chicago, Illinois, U.S.A.

\section{INTRODUCTION}

Metallothionein (MT) is an endogenous low molecular weight protein that is inducible in a variety of eukaryotic cells and has the ability to selectively bind heavy metal ions such as zine and cadmium.' Although the exact physiological role of MT is still not understood, there is strong evidence that MT is involved in providing cellular resistance against the damaging effects of heavy metals and in the regulation of intracellular zinc and copper. $^{23}$

Recently, it has been demonstrated that MT can scavenge radiation-induced reactive oxygen intermediates in vitro ${ }^{4}$ specifically hydroxyl and superoxide radicals, and because of these observations it has been suggested that MT may provide protection against radiation-induced oxidative stress in vivo. Cell lines expressing increased levels of MT have demorstratted resistance to ionizing radiation, ${ }^{5}$ to ulmaviolet radiation, ${ }^{67}$ and also to various DNA damaging agents including melphalan and cis-diaminedichloroplatinum. ${ }^{8}$ It is therefore important to gain some insight into the relationship between cellular MT content and cellular resistance to radiation and other DNA damaging agents.

In this study we investigated the role of MT in providing protection against monochromatic 365-nm UVA radiation, which is known to generate intracellular reactive oxygen species that are involved in both DNA damage and cell killing.9 For this purpose, we used zinc acetate, a potent inducer of MT, to elevate MT levels in V79 Chinese hamster fibroblasts prior to UVA exposure and determined cell survival for uninduced and induced cultures. In order to eliminate any zinc effects other than MT induction, we also isolated and characterized cadmium chloride-resistant clones of V79 cells that have increased steady-state levels of both MT mRNA and protein, and we examined their survival characteristics against 365-nm radiation in the absence of zinc acetate.

\section{METHODS}

V79 cells were routinely culcured in RPMI 1640 media supplemented with $10 \%$ fetal

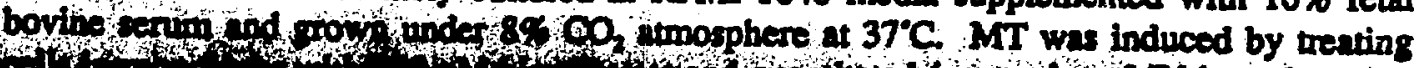




\section{INTRODUCTION}

Metallothionein (MT) is an endogenous low molecular weight protein that is inducible in a variety of eukaryotic cells and has the ability to selectively bind heavy metal ions such as zinc and cadmium. ${ }^{2}$ Although the exact physiological role of MT is still not understood, there is strong evidence that $\mathrm{MT}$ is involved in providing cellular resistance against the damaging effects of heavy metals and in the regulation of intracellular zinc and copper. $^{2,3}$

Recently, it has been demonstrated that MT can scavenge radiation-induced reactive oxygen intermediates in vitro ${ }^{4}$ specifically hydroxyl and superoxide radicals, and because of these observations it has been suggested that MT may provide protection against radiation-induced oxidative stress in vivo. Cell lines expressing increased levels of MT have demonstrated resistance to ionizing radiation, ${ }^{3}$ to ultraviolet radiation, ${ }^{6.7}$ and also to various DNA damaging agents including melphalan and cis-diaminedichloroplatinum. ${ }^{2}$ It is therefore important to gain some insight into the relationship between cellular MT content and cellular resistance to radiation and other DNA damaging agents.

In this study we investigated the role of $\mathrm{MT}$ in providing protection against monochromatic 365-nm UVA radiation, which is known to generate intracellular reactive oxygen species that are involved in both DNA damage and cell killing.' For this purpose, we used zinc acetate, a potent inducer of MT, to elevate MT levels in V79 Chinese hamster fibroblasts prior to UVA exposure and determined cell survival for uninduced and induced cultures. In order to eliminate any zinc effects other than MT induction, we also isolated and characterized cadmium chloride-resistant clones of V79 cells that have increased steady-state levels of both MT mRNA and protein, and we examined their survival characteristics against $365-\mathrm{nm}$ radiation in the absence of zinc acetate.

\section{METHODS}

V79 cells were routinely cultured in RPMI 1640 media supplemented with $10 \%$ fetal bovine serum and grown under $8 \% \mathrm{CO}_{2}$ atmosphere at $37^{\circ} \mathrm{C}$. MT was induced by treating cells in monolayer with $100 \mu \mathrm{M}$ zinc acetate and quantitated (as nmoles of $\mathrm{Cd}$ bound per $\mathrm{mg}$ total protein) by the ${ }^{109} \mathrm{Cd} /$ hemoglobin affinity assay of Eaton and Toal. ${ }^{10}$ For exposure to monochromatic 365-nm UVA radiation, cells were treated with zinc acetate for $24 \mathrm{~h}$, harvested, resuspended in phosphate buffered saline, and irradiated with stirring at room temperature according to Jones et al. ${ }^{13}$ Control cultures were not treated with zinc acetate. Cell survival was measured by incorporation of ${ }^{3} \mathrm{H}$-hypoxanthine into total nucleic acid using the method of Cleaver and Thomas ${ }^{12}$ and survival curves fitted to the linear-quadratic model using the least squares method. $\mathrm{Cl}$ 'nes of V79 cells containing elevated levels of MT were obtained by selecting for increased resistance to cadmium chloride toxicity. Briefly, V79

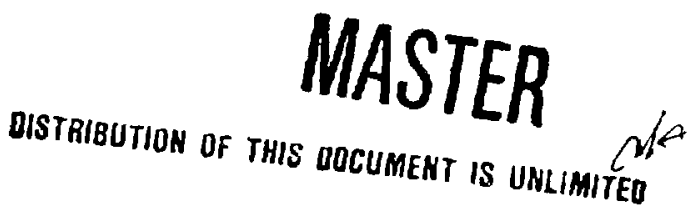


cells were seeded at high density in media containing $20 \mu \mathrm{M}$ cadmium chloride; these cells gave rise to the V79Cd1 clone, which subsequently produced $\mathrm{V} 79 \mathrm{Cd} 2$ and $V 79 \mathrm{Cd} 3$ upon selection at higher cadmium chloride concentrations.

\section{RESULTS}

The induction kinetics of MT by zinc acetate in V79 cells and V79 clones over a $24 \mathrm{~h}$ time course is illustrated in Fig. 1. All four cell lines had similar induction profiles, although the V79 clones showed an increased constitutive level of MT, a reduced initial lag phase of induction, and achieve a higher level of MT by $24 \mathrm{~h}$. V79 cells induced with zinc acetate had a 29 -fold increase in cadmium-binding activity by $24 \mathrm{~h}$ when compared to control cultures. This time point of zinc acetate treatment was chosen to determine cell survival after $365-\mathrm{nm}$ radiation exposures.

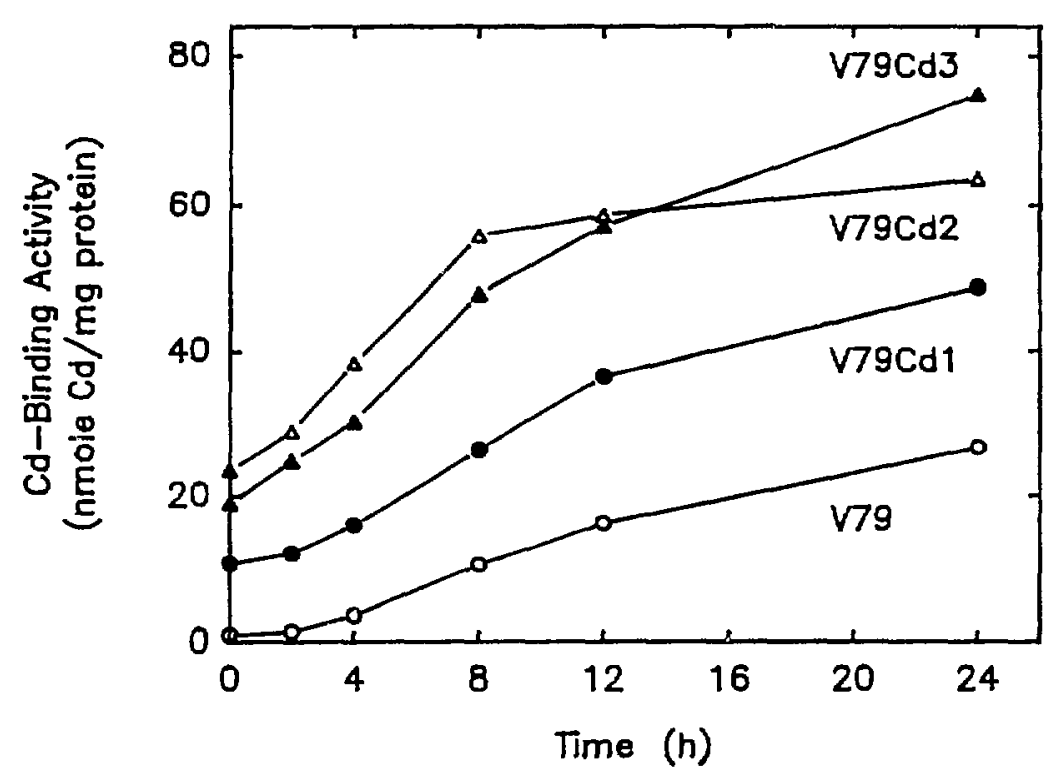

FIGURE 1. Kinetics of MT Induction by Zinc Acetate. V79 cells and V79 cadmiumresistant clones were exposed to $100 \mu \mathrm{M}$ zinc acetate; cellular extracts were prepared and assayed for cadmium-binding activity. Activity is expressed as nmoles of cadmium bound per mg total protein.

Cell survival after 365-nm radiation was next determined for both uninduced and induced cultures of V79 cells in order to characterize any possible protection afforded by MT against UVA radiation-induced stress. Fig. 2 depicts the cell survival kinetics and provides evidence for the involvement of zinc acetate-induced MT in protection against UVA radiation. There is a significant increase in survival over the radiation dose range tested for the treated cells relative to the uninduced control cells. At a dose of $0.8 \mathrm{MJ} / \mathrm{m}^{2}$, the induced culture had $19 \%$ viable cells remaining, compared to $4 \%$ remaining in the uninduced culture.

There is current evidence from in vivo data that zinc deficiency causes lethal cellular damage by increasing lipid peroxidation of cell membranes and that supplementa! zinc is able to stabilize membranes against such damage by acting either as a free radical

\section{DISCLAIMER}

This report was prepared as an account of work sponsored by an agency of the United States Government. Neither the United States Government nor any agency thereof, nor any of their employees, makes any warranty, express or implied, or assumes any legal liability or responsibility for the accuracy, completeness, or usefulness of any information, apparatus, product, or process disclosed, or represents that its use would not infringe privately owned rights. Reference herein to any specific commercial product, process, or service by trade name, trademark, manufacturer, or otherwise does not necessarily constitute or imply its endorsement, recommendation, or favoring by the United States Government or any agency thereor. The views 


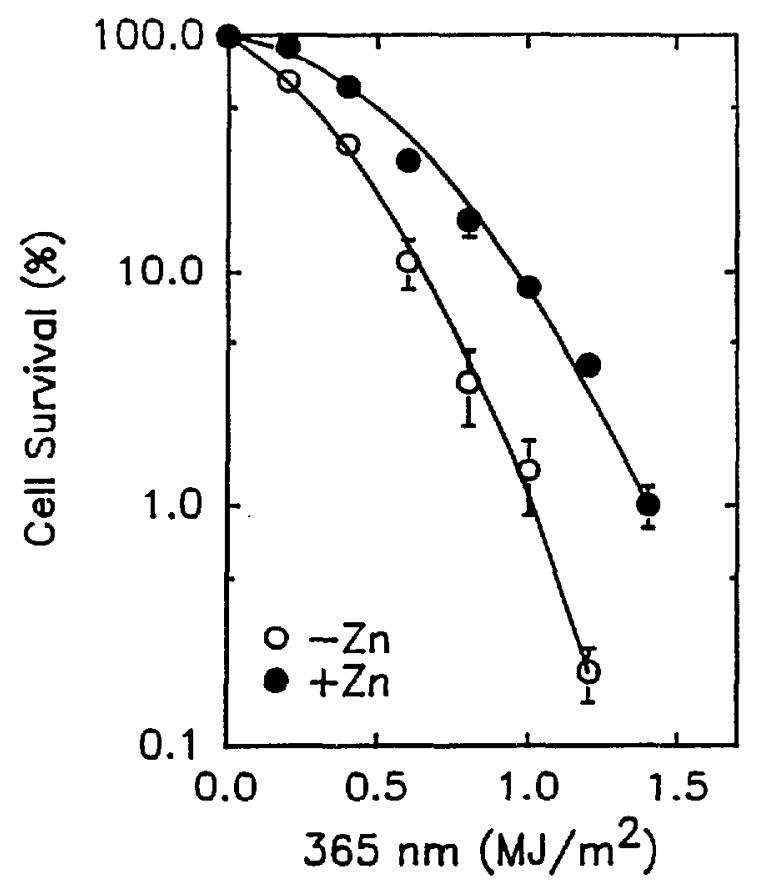

FIGURE 2. 365-nm Survival Curves of Control and Zinc Acetate-Induced V79 Cells. Cell cultures were harvested, resuspended in phosphate buffered saline at a cell density of $2 \times 10^{6}$ cells $/ \mathrm{ml}$, and exposed to $365-\mathrm{nm}$ radiation.

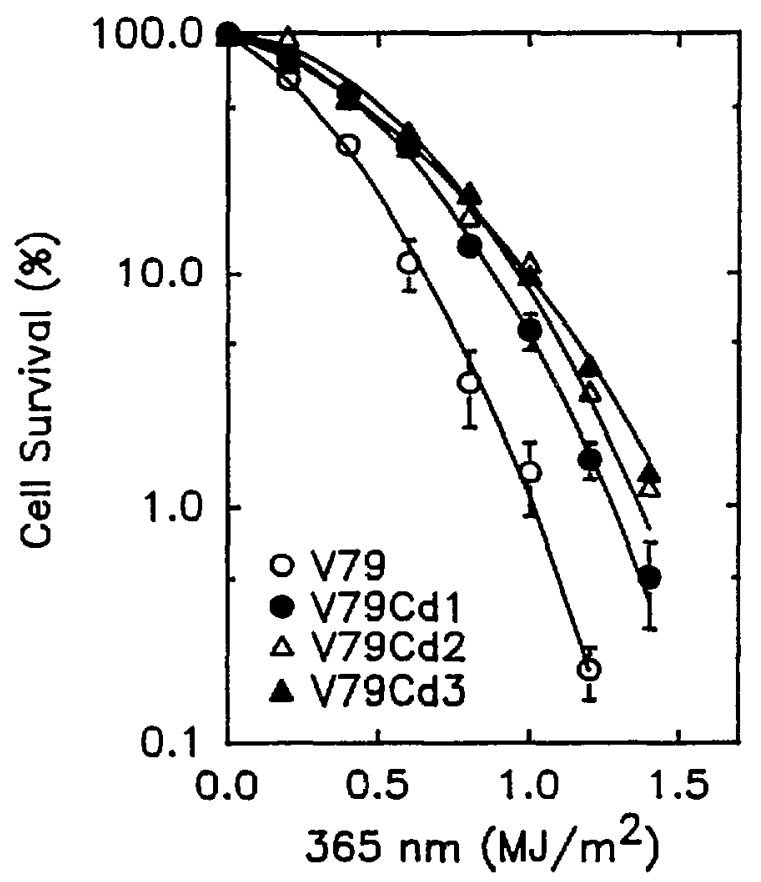

FIGURE 3. 365-nm Cell Survival Curves of V79 Cadmium-Resistant Clones. V79 clones containing elevated MT levels were irradiated with $365-\mathrm{nm}$ radiation without prior exposure to zinc acetate. 
scavenger or by reducing intracellular free radical formation. ${ }^{13}$ In order to eliminate any possibility that zinc alone confers protection against UVA-induced photooxidative damage, we isolated V79 cells with varying steady-state levels of both MT mRNA and protein by selecting for resistance against cadmium chloride and determined their survival against 365$\mathrm{nm}$ radiation in the absence of zinc acetate. Figure 3 represents the survival curves of the V79 clones $\mathrm{V} 79 \mathrm{Cd} 1, \mathrm{Cd} 2$, and $\mathrm{Cd} 3$ against $365-\mathrm{nm}$ radiation with no zinc present. All three clones exhibited increased survival comparable to the zinc acetate-induced V79 cultures. Cell survival at $0.8 \mathrm{MJ} / \mathrm{m}^{2}$ for uninduced cultures of $\mathrm{V} 79 \mathrm{Cd} 1, \mathrm{Cd} 2$, and $\mathrm{Cd} 3$ was $14 \%, 20 \%$, and $19 \%$, respectively. These results tend to support the hypothesis that the increased cellular MT levels protect cells against UVA radiation by scavenging free radicals and that zinc itself is not responsible for the observed protection.

\section{DISCUSSION}

Ultraviolet radiation is generally divided into three wavelength regions designated as UVC (290 nm and below), UVB (290 to $320 \mathrm{~nm}$ ), and UVA (320 nm to visible light). There is now sufficient evidence to indicate that exposure to UVA radiation, a major component of sunlight, represents an important oxidative stress to mammalian cells through the intracellular generation of reactive oxygen intermediates. We have demonstrated that MT, a free radical scavenger, can ameliorate the cytotoxic effects of monochromatic 365 -nm UVA radiation and suggest that this occurs by MT reducing cellular oxidative stress and photooxidative damage through its interaction with certain reactive oxygen species. The nature of the reactive oxygen intermediates produced during UVA radiation may be similar to those produced by other DNA damaging agents suggesting that MT may provide a general radical scavenging mechanism for specific cell types. The type of UVA-mediated photooxidative damage that MT protects against is not yet known, but it may involve protection at the level of DNA since it is well known that wavelengths in the UVA range can cause various types of DNA damage including single-strand breaks and DNA-protein crosslinks. ${ }^{14}$ We are presently investigating whether MT can protect cellular DNA from the damaging effects of UVA radiation.

\section{REFERENCES}

1. Hamer, D.H. Metallothionein. Ann. Rev. Biochem. 55:913-951; 1986.

2. Compere, S.J.; Palmiter, R.D. DNA methylation controls the inducibility of the mouse metallothionein-I gene in lymphoid cells. Cell 25:233-240; 1981.

3. Schmidt, C.J.; Jubier, M.F.; Hamer, D.H. Structure and expression of two human metallothionein-I isoform genes and a related pseudogene. J. Biol. Chem. 260:7731-7737; 1985.

4. Thornalley, P.J.; Vasak, M. Possible role for metallothionein in protection against radiation-induced oxidative stress. Kinetics and mechanism of its reaction with superoxide and hydroxyl radicals. Biochem. Biophys. Acta 827:36-44; 1985.

5. Renan, M.J.; Dowman, P.I. Increased radioresistance of tumor cells exposed to metallothionein-inducing agents. Radiat. Res. 120:442-455; 1989.

6. Fornace Jr., A.J.; Papathanasiou, M.A.; Tarone, R.E.; Wong, M.; Mitchell, J.B.; Hamer, D.H. DNA-damage inducible genes in mammalian cells. In: Fifth International Conference on Environmental Mutagens. Alan R. Liss, Inc.; 1989.

7. Hanada, K.; Siebert, E.; Gange,R.W. UVB resistance in cultured human cells treated with cadmium chloride. Photochem. Photobio. 51S:SAM-A30 abstr. (1990).

8. Kelley, S.L.; Basu, A.; Teicher, B.A.; Hacker, M.P.; Hamer, D.H.; Lazo, J.S. Overexpression of metallothionein confers resistance to anticancer drugs. Science 242:1813-1815; 1988. 
9. Peak, M.J.; Peak, J.G. Molecular photobiology of UVA. In: Urbach, F.; Gange, R.W.; eds. The Biological Effects of UVA Radiations. New York: Plenum Press; 1986.

10. Eaton, D.L.; Toal, B.F. Evaluation of the $\mathrm{Cd}$ /hemoglobin affinity assay for the rapid determination of metallothionein in biological tissues. Toxicol. Appl. Pharmacol. 42:583-588; 1982.

11. Jones, C.A.; Huberman, E.; Cunningham, M.L.; Peak, M.J. Mutagenesis and cytotoxicity in human epithelial cells by far- and near-ultraviolet radiations: action spectra. Radiat. Res. 110:244-254; 1987.

12. Cleaver, J.E.; Thomas, G.H. Rapid diagnosis of sensitivity to ultraviolet light in fibroblasts from dermatologic disorders, with particular reference to xeroderma pigmentosum. J. Invest. Dermatol. 90:467-471; 1988.

13. Bray, T.M.; Bettger, W.J. The physiological role of zinc as an antioxidant. Free Radical Biol. Med. 8:281-291; 1990.

14. Peak, M.J.; Peak, J.G. DNA-to-protein crosslinks and backbone breaks caused by farand near-ultraviolet, and visible light radiations in mammalian cells. In: Grossman, L.; Upton, A.C.; eds. Mechanisms of DNA Damage and Repair. New York: Plenum Press; 1986.

\section{ACKNOWLEDGEMENTS}

This work was supported in part by PHS Grants RO1-CA34492 and RO1 CA37848 awarded by the National Cancer Institute, U. S. Department of Health and Human Services, and in part by the U. S. Department of Energy, Office of Health and Environmental Research, under contract No. W-31-109-ENG-38. The authors thank David Nadziejka for his editorial review and Kay Bexson for her excellent secretarial assistance. 